\title{
Association of accessory sphenoid septa with variations in neighbouring structures
}

\author{
F AKSOY, A YENIGUN, S S GOKTAS, O OZTURAN \\ Department of Otorhinolaryngology, Faculty of Medicine, Bezmialem Vakif University, Fatih, Istanbul, Turkey
}

\begin{abstract}
Objective: This study aimed to examine the relationship of the accessory sphenoidal septum with surrounding vital structures and their variations.

Methods: This cross-sectional retrospective study investigated the prevalence of accessory sphenoidal septa and their relationship with variations in surrounding vital structures in coronal and axial paranasal computed tomography images.

Results: Coronal and axial computed tomography images of 347 patients were assessed to evaluate the presence of accessory sphenoidal septa. Accessory sphenoidal septa originated from the internal carotid artery in 47.7 per cent of patients and from the optic nerve in 17.5 per cent. These structures were significantly associated with protrusion of the optic nerve, internal carotid canal or Vidian nerve canal.

Conclusion: Accessory sphenoidal septa can originate from the internal carotid artery or the optic nerve. Therefore, the presence of an accessory sphenoidal septum indicates an increased risk of surgical complications including internal carotid artery injury and loss of vision due to optic nerve injury.
\end{abstract}

Key words: Paranasal Sinuses; Sphenoid Sinus; Optic Nerve; Carotid Arteries; Computed X Ray Tomography

\section{Introduction}

Endoscopic endonasal transsphenoidal surgery is commonly used to treat sphenoidal sinus disorders and sellar, suprasellar and parasellar tumours. ${ }^{1}$ The anatomy of the sphenoidal sinus should be familiar to surgeons because of its proximity to the optic nerve, carotid artery and skull base. ${ }^{2}$ The sphenoidal sinus is usually divided asymmetrically into several parts by one or more vertical septa. It is important to determine the location of septa and their relationship with glandular and neurovascular structures to avoid surgical complications. $^{2}$ In transsphenoidal pituitary surgery, pre-operative assessment by computed tomography (CT) scanning is the accepted 'gold standard'.

Owing to the wide variety of anatomical variations of the sphenoid sinus, it is important to determine the details of septation to design a safe endoscopic approach, especially in the absence of intra-operative navigation. ${ }^{2}$ In endoscopic sinus surgery, protrusion of the internal carotid artery into the sphenoid sinus may alter the septal position or seriously injure the septal origin. ${ }^{4}$

This study aimed to assess accessory septation of the sphenoid sinuses and its relationship with morphological variants of neighbouring anatomical structures.

\section{Materials and methods}

This retrospective study was approved by the local clinical research ethics committee. Axial paranasal sinus CT sections of $3 \mathrm{~mm}$ thickness were obtained using a Philips Brilliance 64-slice CT scanner (Philips Medical Imaging, Best, The Netherlands). Axial CT scanning was done with patients in a supine position, with the head positioned such that the hard palate was parallel to the floor and the sagittal plane was perpendicular to the floor. All orientations of CT images are needed for assessing sinonasal, otological and maxillofacial injuries. Patients with maxillofacial trauma, nasal polyposis or sinus anomalies and those who had previously undergone sinus surgery were excluded from the study.

Coronal and axial sectional CT images of 347 consecutive patients were evaluated for the prevalence of accessory sphenoid septa and the co-occurrence of morphological variants in neighbouring anatomical structures. Accessory sphenoidal septa were defined as septa dividing the sphenoid sinus longitudinally and extending to the base of the sinus (either completely or incompletely) other than the natural sphenoid septum (Figures 1 and 2).

Based on CT findings, Vidian nerve configuration was classified into three types using the classification 


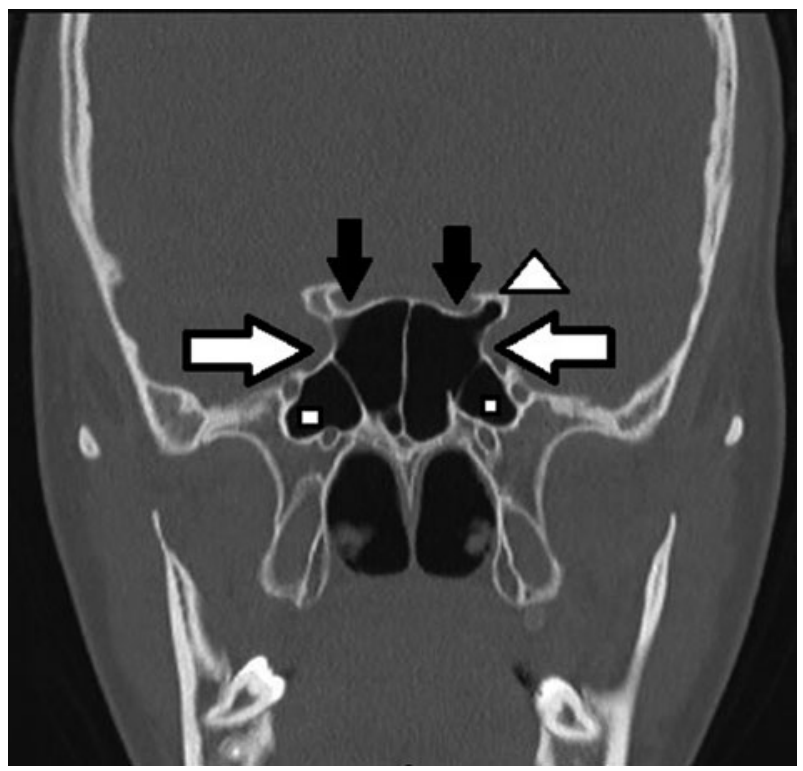

FIG. 1

Coronal computed tomography image showing bilateral protrusion of the optic nerve (black arrows), left anterior clinoid pneumatisation (white arrowhead), pneumatisation of bilateral pterygoid process (white squares) and bilateral internal carotid artery originating from the accessory sphenoid septa (white arrows)

system introduced by Lee et al. ${ }^{5}$ : in type 1 , the Vidian nerve canal protrudes completely into the sphenoid sinus; in type 2, the Vidian nerve canal partially protrudes into the sphenoid sinus or into the floor of the sphenoid sinus; and in type 3, the Vidian nerve canal is completely embedded within the sphenoid corpus.

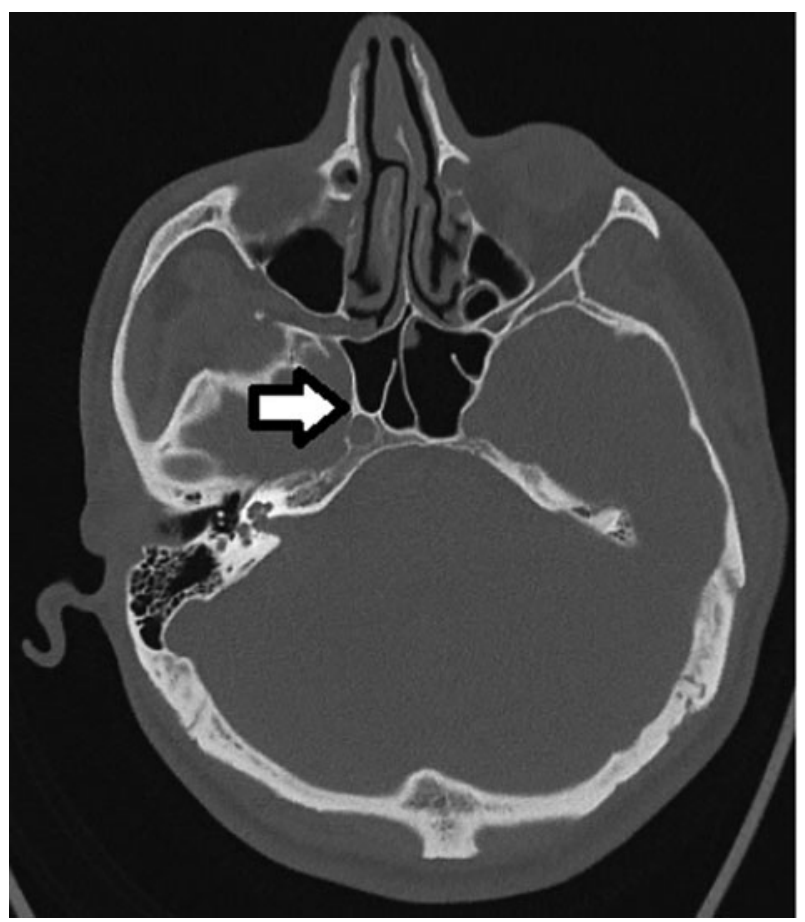

FIG. 2

Axial computed tomography image showing the left optic nerve originating from an accessory sphenoid septa (white arrow).
The relationship of optic nerve with the posterior paranasal sinus is classified as protrusion and dehiscence. $^{2,3}$ The classification of protrusion is made when more than half of the optic nerve and internal carotid artery protrude into the sphenoid sinus cavity, as seen in coronal CT sections.

Data were statistically analysed using the chi-square test. A $p$ value of more than 0.05 was deemed to be statistically significant.

\section{Results}

A total of 347 adult patients examined by coronal and axial paranasal sinus CT were included: these comprised 205 men (59.1 per cent) and 142 women (40.9 per cent). Patient age ranged between 18 and 79 years (mean \pm standard deviation, $35.28 \pm 13.75$ years).

Accessory sphenoid septa and accompanying morphological variation in neighbouring structures were evaluated in 694 sides (right and left) of 347 patients. Accessory sphenoidal septa were detected in 172 patients (49.5 per cent): in the right side in 48.1 per cent of patients and in the left side in 51.7 per cent of patients. Accessory sphenoidal septa originating from the internal carotid artery (ICA) were detected in 47.7 per cent of patients: 49.2 per cent for the right side and 46.4 per cent for the left side. Accessory sphenoidal septa originating from the optic nerve were detected in 17.5 per cent of patients: 17.3 per cent for the right side and 17.6 per cent for the left side. Accessory sphenoidal septa originating from both the ICA and optic nerve were found in 1.3 per cent of patients.

The association of ICA protrusion with accessory sphenoidal septa was examined. Internal carotid artery protrusion was associated with right-sided accessory sphenoidal septa in 53.9 per cent of patients, while only 38.3 per cent of patients without a rightsided accessory sphenoidal septum had an ICA protrusion $(p=0.003)$. Internal carotid artery protrusion was associated with left-sided accessory sphenoidal septa in 63.6 per cent of patients, while only 44.4 per cent of patients without a left-sided accessory sphenoidal septum had an ICA protrusion $(p=0.000)$. Thus, ICA protrusion was significantly associated with the presence of accessory sphenoidal septa in both the right and left sides (Table I). The association of optic nerve protrusion with accessory sphenoidal septa was also examined. Coexistence of optic nerve protrusion and a right-sided accessory sphenoidal septum was seen in 44.9 per cent of patients, while only 32.2 per cent of those without a right-sided accessory sphenoidal septum had optic nerve protrusion $(p=0.01)$. Coexistence of optic nerve protrusion and a left-sided accessory sphenoidal septum was seen in 44.9 per cent of patients, while only 32.7 per cent of patients without a left-sided accessory sphenoidal septum had optic nerve protrusion $(p=0.014)$. Thus, optic nerve protrusion was significantly associated with the 
TABLE I CONCURRENCE OF ACCESSORY SPHENOID SEPTA WITH NEIGHBOURING MORPHOLOGICAL VARIANTS

\begin{tabular}{lcccccccc}
\hline Variation & \multicolumn{3}{c}{ Right-sided ASS } & & \multicolumn{3}{c}{ Left-sided ASS } \\
\cline { 2 - 3 } & Presence (\%) & Absence (\%) & $p$ value & & Presence (\%) & Absence (\%) & $p$ value \\
\hline VN canal protrusion (type 1) & 52.1 & 36.1 & 0.008 & & 53.4 & 33.3 & 0.000 \\
Pneumatisation of pterygoid process & 58.1 & 38.3 & 0.000 & & 59.1 & 43.9 & 0.003 \\
Pneumatisation of anterior clinoid process & 28.7 & 15.0 & 0.001 & & 27.8 & 18.7 & 0.030 \\
Optic nerve protrusion & 44.9 & 32.2 & 0.01 & & 44.9 & 32.7 & 0.014 \\
ICA protrusion & 53.9 & 38.3 & 0.003 & & 63.6 & & 44.4 & 0.000 \\
\hline
\end{tabular}

ASS = accessory sphenoidal septum; VN = Vidian nerve; ICA = internal carotid artery

presence of accessory sphenoidal septa for both the right and left sides (Table I).

The association of Vidian nerve canal protrusion with accessory sphenoidal septa was also examined. Different types of Vidian nerve canal configuration coexisted with right-sided accessory sphenoidal septa: type 1 was present in 52.1 per cent of patients; type 2 in 32.3 per cent of patients; and type 3 in 15.6 per cent. The proportion of patients without an accessory sphenoidal septum but with Vidian nerve canal protrusion was lower: type 1 was present in 36.1 per cent of patients; type 2 in 39.4 per cent; and type 3 in 24.4 per cent of patients $(p=0.008)$. Different types of Vidian nerve canal configuration also coexisted with left-sided accessory sphenoidal septa: type 1 was present in 53.4 per cent of patients; type 2 in 34.7 per cent of patients; and type 3 in 11.9 per cent of patients. The proportion of patients without an accessory sphenoidal septum but with Vidian nerve canal protrusion was lower: type 1 was present in 33.3 per cent of patients; type 2 in 39.8 per cent of patients; and type 3 in 26.9 per cent of patients $(p=0.000)$. Vidian nerve canal protrusion was significantly associated with the presence of accessory sphenoidal septa for both the right and left sides (Table I).

The association of pterygoid process pneumatisation with accessory sphenoidal septa was also examined. A pterygoid process and a right-sided accessory sphenoidal septum co-occurred in 58.1 per cent of patients, while only 38.3 per cent of those without a rightsided accessory sphenoidal septum had a pterygoid process $(p=0.000)$. Similarly, a pterygoid process and a left-sided accessory sphenoidal septum cooccurred in 59.1 per cent of patients, while only 43.9 per cent of those without a left-sided accessory sphenoidal septum had a pterygoid process $(p=0.003)$. The association between a pterygoid process and the presence of accessory sphenoidal septa was statistically significant for both the right and left sides (Table I).

The association of pneumatisation of the anterior clinoid process and accessory sphenoidal septa were also examined. Coexistence of an anterior clinoid process and right-sided accessory sphenoidal septa was seen in 28.7 per cent of patients, while only 15.0 per cent of those without a right-sided accessory sphenoidal septum had an anterior clinoid process $(p=0.001)$. Coexistence of an anterior clinoid process and left-sided accessory sphenoidal septum was seen in 27.8 per cent of patients, while only 18.7 per cent of patients with an anterior clinoid process had a left-sided accessory sphenoidal septum ( $p=$ $0.03)$. An anterior clinoid process was significantly associated with the presence of accessory sphenoidal septa in both the right and left sides (Table I).

\section{Discussion}

Knowledge of anatomical variations in this zone is important because endoscopic endonasal sphenoidal pituitary surgery and anterior skull base surgery are becoming more common. ${ }^{6}$ Wide anatomical variations in the sphenoid sinus can lead to injury to vital neurovascular and glandular structures during surgery. ${ }^{7}$ The sphenoid sinus is usually divided into two parts by the intersphenoidal septum. Idowu et al. reviewed the CT scans of 60 patients and saw an accessory sphenoidal septum in only one patient. ${ }^{2}$ In contrast, Hamid et al. reported the absence of a sphenoid septum in 10.8 per cent of patients. ${ }^{4}$ The sphenoid septum was absent in none of the patients in the present study.

The prevalence of multiple septations in sphenoid sinus was reported by Sareen et al. as 80 per cent, by Idowu et al. as 48.3 per cent and by Sapci et al. as 81.8 per cent. ${ }^{2,8,9}$ In the present study, multiple septation was present in 49.4 per cent of patients.

In a study of 92 patients, Sirikci et al. reported that internal carotid artery (ICA) protrusion had a prevalence of 26.1 per cent. ${ }^{10}$ Fujii et al. reported that of the 25 cadavers included in their series, 8 per cent had ICA dehiscence in the sphenoid sinus. ${ }^{11}$ Ozturan et al. reported the prevalence of both ICA protrusion and dehiscence as 2.8 per cent in the absence of an Onodi cell; when the Onodi cell was present, these rates increased to 59 per cent for ICA protrusion and 20.8 per cent for ICA dehiscence. ${ }^{12}$ In the present study, the accessory sphenoidal septum originated in the ICA in 47.7 per cent of all cases. Nevertheless, the presence of accessory sphenoidal septum was significantly associated with ICA protrusion $(p=0.003$ for the right side, $p=0.000$ for the left side). This result indicates that the presence of an accessory sphenoidal septum may increase the risk of ICA injury. 
Optic nerve protrusion or dehiscence could increase the risk of injury from sphenoid sinus surgery for sphenoidal disorders. When sphenoid sinus surgery causes optic nerve injury, the risk of blindness is very high. ${ }^{13}$ Hyperpneumatisation of both the ethmoid and sphenoid sinuses increased the risk of optic nerve injury during surgery. ${ }^{7}$ An infected sphenoid sinus or a mucocele that obstructs the optic canal could cause a visual deficit due to ischaemia or venous insufficiency. An increase in optic nerve protrusion has been reported with the presence of an Onodi cell. ${ }^{10,14}$ In this study, the accessory sphenoidal septum originated in the optic nerve in 17.5 per cent of all cases. Additionally, the presence of an accessory sphenoidal septum was significantly associated with optic nerve protrusion ( $p=0.01$ for the right side, $p=0.014$ for the left side). Therefore, due to the risk of optic nerve injury during sinus surgery, the presence of an accessory sphenoidal septum presence should be considered.

Vidian canal configuration was classified by Lee et al. into three types according to the relationship with the sphenoid sinus. ${ }^{5}$ Lang and Keller reported that type 3 (in which the Vidian canal is embedded within the corpus of the sphenoid bone) was the most common, occurring in 38 per cent of 150 cases. $^{15}$ Yazar et al. reported that type 2 was the most common, occurring in 54 per cent of 150 cases. ${ }^{16}$ Liu et al. reported that type 3 was the most common type, occurring in 53.4 per cent of 341 cases. $^{17}$ Ozturan et al. analysed the Vidian canals of 999 patients and found that 66.5 per cent were type 2 ; the presence of Onodi cells did not alter this proportion. ${ }^{12}$ In the present study, an increased incidence of accessory sphenoidal septa was associated with an increasing incidence of type 1 Vidian canals (that mostly protrude into the sphenoid sinus; $p=0.008$ for the right, $p=$ 0.000 for the left). This result suggests that the presence of accessory sphenoidal septa is related to an increased risk of Vidian nerve injury during sphenoid sinus surgery.

- In endoscopic sinus surgery, protrusion of the internal carotid artery or optic nerve into the sphenoid sinus may seriously alter the septum or its origin

- In this study, accessory sphenoid septa originated in the internal carotid artery (47.7 per cent) or the optic nerve (17.5 per cent)

- The presence of accessory sphenoid septa was related to protrusion of the optic nerve or internal carotid artery

- This study defined sphenoid septa located vertically within the sphenoid sinus other than the natural sphenoid septum as accessory sphenoid septa
This study provides the first definition of an accessory sphenoidal septum as a sphenoid septum located vertically within the sphenoid sinus (other than the natural sphenoid septum). It therefore provides a new approach for pre-operative investigations into accessory sphenoidal septa based on their relationship with neighbouring vital anatomical structures, which may help avoid serious complications.

\section{Conclusion}

Accessory sphenoid septa are septal variations that are present in addition to the natural septum. They may extend completely or partially into the sphenoid sinus, and may originate within or be located near to anatomically important structures. In this study, an accessory sphenoidal septum was seen in 49.5 per cent of patients: 47.7 per cent of accessory sphenoidal septa originated in the internal carotid artery (ICA) and 17.5 per cent in the optic nerve. Thus, the presence of an accessory sphenoidal septum indicates an increased risk of surgical complications including ICA injury or loss of vision due to optic nerve injury.

\section{References}

1 Kieff DA, Busaba N, Treatment of isolated sphenoid sinus inflammatory disease by endoscopic sphenoidotomy without ethmoidectomy. Laryngoscope 2002;112:2186-8

2 Idowu OE, Balogun BO, Okoli CA. Dimensions, septation, and pattern of pneumatization of the sphenoidal sinus. Folia Morphol 2009;68:228-32

3 Unlu A, Meco C, Ugur HC, Comert A, Ozdemir M, Elhan A. Endoscopic anatomy of sphenoid sinus for pituitary surgery. Clin Anat 2008;21:627-32

4 Hamid O, El Fiky L, Hassan O, Kotb A, El Fiky S. Anatomic variations of the sphenoid sinus and their impact on trans-sphenoid pituitary surgery. Skull Base 2008;18:9-15

5 Lee JC, Kao CH, Hsu CH, Lin YS. Endoscopic transsphenoidal vidian neurectomy. Eur Arch Otorhinolaryngol 2011;268: $851-6$

6 Cho JH, Kim JK, Lee JG, Yoon JH. Sphenoid sinus pneumatization and its relation to bulging of surrounding neurovascular structures. Ann Otol Rhinol Laryngol 2010;119:646-50

7 Kantarci M, Karasen RM, Alper F, Onbas O, Okur A, Karaman A. Remarkable anatomic variations in paranasal sinus region and their clinical importance. Eur J Radiol 2004;50:296-302

8 Sareen D, Agarwal A, Kaul J, Sethi A. Study of sphenoid sinus anatomy in relation to endoscopic surgery. Int J Morphol 2005; 23:261-6

9 Sapci T, Derin E, Almaç S, Cumali R, Saydam B, Karavuş M. The relationship between the sphenoid and the posterior ethmoid sinuses and the optic nerves in Turkish patients. Rhinology 2004;42:30-4

10 Sirikci A, Bayazit YA, Bayram M, Mumbuç S, Güngör K, Kanlikama M. Variations of sphenoid and related structures. Eur Radiol 2000;10:844-8

11 Fujii K, Chambers SM, Rhoton AL. Neurovascular relationships of the sphenoid sinus. A microsurgical study. J Neurosurg 1979; 50:31-9

12 Ozturan O, Yenigun A, Degirmenci N, Aksoy F, Veyseller B. Co-existence of the Onodi cell with the variation of perisphenoidal structures. Eur Arch Otorhinolaryngol 2013;270:2057-63

13 Maniglia AJ. Fatal and major complications secondary to nasal and sinus surgery. Laryngoscope 1989;99:276-83

14 Unal B, Bademci G, Bilgili YK, Batay F, Avci E. Risky anatomic variations of sphenoid sinus for surgery. Surg Radiol Anat 2006;28:195-201

15 Lang J, Keller H. The posterior opening of the pterygopalatine fossa and the position of the pterygopalatine ganglion. Gegenbaurs Morphol 1978;124:207-14 
16 Yazar F, Cankal F, Haholu A, Kiliç C, Tekdemir I. CT evaluation of the vidian canal localization. Clin Anat 2007;20:751-4

17 Liu SC, Wang HW, Su WF. Endoscopic vidian neurectomy: the value of preoperative computed tomographic guidance. Arch Otolaryngol Head Neck Surg 2010;136:595-602

Address for correspondence:

Dr A Yenigun,

Department of Otorhinolaryngology, Faculty of Medicine,

Bezmialem Vakif University,
Adnan Menderes Bulvarı Vatan Caddesi 34093, Fatih, İstanbul, Turkey

Fax: +902124531870

E-mail: alperyenigun@gmail.com

Dr A Yenigun takes responsibility for the integrity of the content of the paper

Competing interests: None declared 